\title{
Atypical myocardial infarction on a cruise ship
}

\section{Christopher Taylor}

Independent Contractor Cruise Ship Physician, Mansfield, Nottinghamshire, England

\begin{abstract}
A previously asymptomatic 44-year-old male crewmember on a cruise ship experienced several brief episodes of acute chest pain within a short time frame. He was ultimately diagnosed with myocardial infarction; $5 \mathrm{~h}$ earlier he had been discharged from the ship's medical centre after almost $8 \mathrm{~h}$ of monitoring to rule-out infarction. Subsequent angiography ashore revealed a 99\% occlusion of the right coronary artery. This case highlights the dangers of over-reliance on shipboard cardiac enzyme testing to clear a patient with chest pain.
\end{abstract}

(Int Marit Health 2015; 66, 1: 22-24)

Key words: acute chest pain, acute coronary syndrome, myocardial infarction, cardiac enzymes, electrocardiogram, maritime medicine

\section{INTRODUCTION}

Acute chest pain is a medical challenge, especially at sea. What is the cause, can it be treated aboard, and if not, what can be done until safe evacuation to definitive care is possible? A 44-year-old male seafarer with a 6-h history of episodic chest pain is presented; investigation and monitoring in the ship's medical centre disclosed no initial cause for concern.

\section{CASE REPORT}

Just before noon, directly after a cigarette and an espresso coffee prior to starting his watch duty, a previously asymptomatic 44-year-old male crewmember, with no known risk factors for cardiac disease other than moderate cigarette smoking, experienced a first ever episode of acute chest pain.

The pain was a pressure in the chest, with no radiation and no associated symptoms. After 2 min the pain resolved spontaneously and completely, only to return $2 \mathrm{~h}$ later, with the same characteristics and for a similar duration. In-between these episodes he was asymptomatic and able to perform his normal duties.

Approximately $6 \mathrm{~h}$ after the first symptom, the pain recurred for a third time. This episode was also associated with caffeine and a cigarette. On this occasion the pain was slightly more forceful, rated by him as 2 out of 10 on a verbal pain scale (where 0 represents no pain at all) and at this point he decided to seek medical attention.

The initial examination was unremarkable. Blood pressure was normal and similar in each arm; the electrocardiogram (ECG) was non-diagnostic (Fig. 1) and the initial cardiac enzymes were within normal limits.

A working diagnosis of atypical chest pain, possibly due to oesophageal spasm, was made. Antacids were prescribed along with benzodiazepines as it was felt that patient anxiety was not assisting resolution. Neither nitroglycerin nor opiates were administered and the pain settled spontaneously. The patient was admitted to "rule out myocardial infarction (MI)" by means of serial cardiac enzymes and ECGs.

During the admission the patient's pain level fluctuated between 0 and 1 out of 10 , but mostly he was pain free. Cardiac enzymes were repeated after approximately $6 \mathrm{~h}$ of monitoring (corresponding to approximately $13 \mathrm{~h}$ from his very first symptom and $7 \mathrm{~h}$ from the time of maximal pain) and remained within normal limits. No changes were detected on serial ECG traces.

Just before 3 a.m., after almost $8 \mathrm{~h}$ of monitoring, he was comfortable, pain-free and allowed back to his cabin. He was asked to return at 8 a.m. in the morning for review. 
A. At initial presentation: 7 p.m.
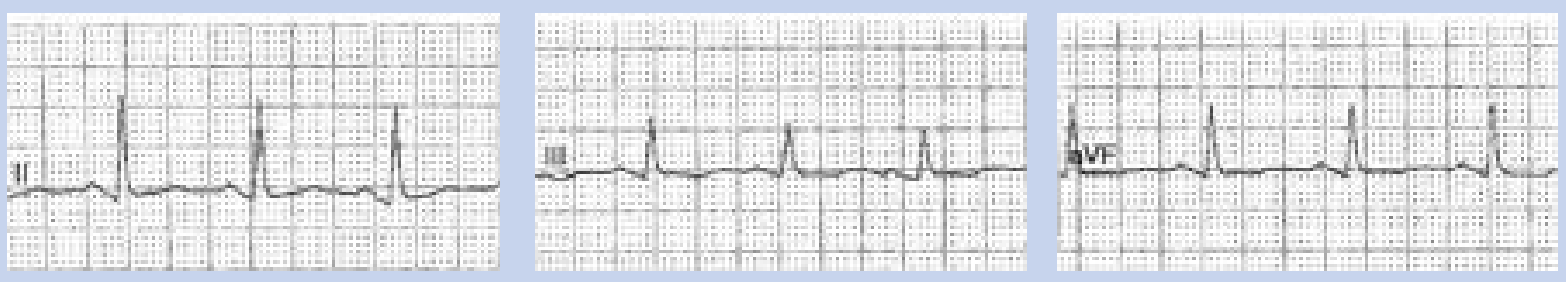

B. At second visit: 8 a.m.

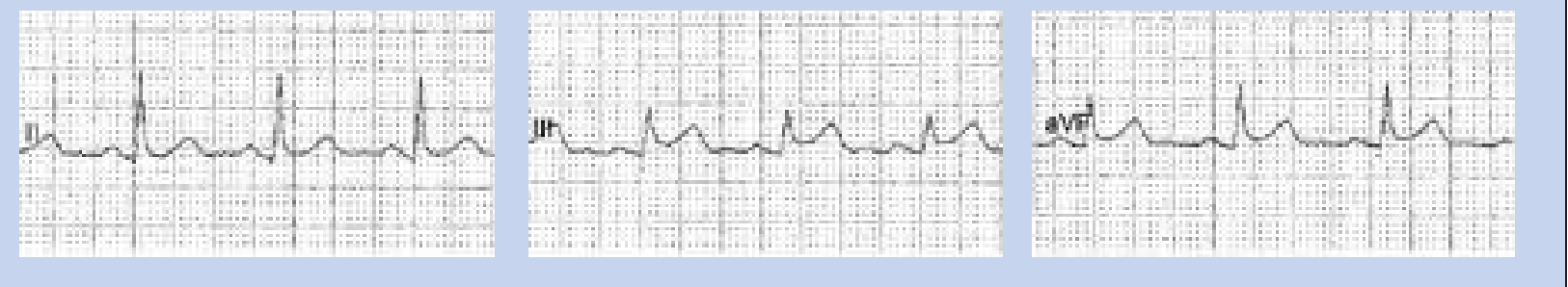

Figure 1. Electrocardiograms of the inferior leads taken at initial presentation $(\mathbf{A})$ and when the patient returned with severe chest pain $13 \mathrm{~h}$ later (B). The second trace shows the development of ST segment elevation in leads III and aVF

When the patient returned at 8 a.m., he was clutching his chest and sweating profusely, the pain having recurred with great severity just a few minutes earlier.

The ECG now showed acute inferior wall MI with ST segment elevation in the inferior leads II and aVF (Fig. 1) and reciprocal ST segment depression in antero-lateral leads I, aVL and $\mathrm{V}_{3}$ through $\mathrm{V}_{6}$.

The ship was docked at the time in a major port so, after initial stabilisation, the patient was transferred directly for emergency percutaneous coronary intervention rather than undergoing fibrinolysis on board. Cardiac enzymes levels were repeated prior to his transfer and all remained within normal limits, corresponding to approximately $20 \mathrm{~h}$ from his initial chest pain and $13 \mathrm{~h}$ from the time of first presentation. In hospital, angiography subsequently showed a 99\% occlusion of the right coronary artery, which was successfully stented.

\section{DISCUSSION}

All modern cruise ships are required to have the capability of performing ECGs and measuring cardiac enzymes [1]. Admission to rule out MI is a common event on cruise ships with an elderly cruising population and an increasingly mature workforce.

When first assessed, the patient described was thought unlikely to be experiencing cardiac chest pain, based on the nature of his symptoms and an assessment of pre-existing risk factors. Each episode of pain lasted only a minute or two and the association with caffeine and nicotine intake suggested spasmodic oesophagitis as a more likely diagnosis. Accordingly he was treated with antacids and anxiolytics. Anti-platelet and anticoagulation therapies were not insti- gated because the likelihood of acute coronary syndrome (ACS) was felt to be very low.

Within the appropriate clinical setting, elevated levels of troponin can indicate a diagnosis of non-ST elevation MI as well as confirm ST elevation MI, but unstable angina, the third subset of ACS patients, remains a distinct possibility when cardiac enzymes do not rise above the normal range in patients with chest pain.

In retrospect it is apparent that this patient was experiencing unstable angina at initial presentation, albeit with a very short history of atypical symptoms, and that this was followed by $\mathrm{Ml}$ within $24 \mathrm{~h}$ of symptom onset. The absence of elevated cardiac enzymes when the patient returned, $13 \mathrm{~h}$ after the initial presentation and $5 \mathrm{~h}$ after discharge, suggests that infarction occurred after the period of in-patient monitoring and observation.

The reported probability of secondary events occurring subsequent to an episode of ACS without elevated troponins varies greatly; 30 -day mortality rates from $0.3 \%$ to $4.5 \%$ $[2,3]$ have been described. Rates of subsequent $\mathrm{MI}$ in unstable angina patients have been recorded at $2.3 \%$ to $4.3 \%$ in a 43 day follow up period [4] and an incidence of $5.4 \%$ was found for the combined end-point of death or MI in unstable angina 11 weeks after an episode of ACS [5].

The patient in this case report experienced a subsequent cardiac event just $13 \mathrm{~h}$ after his initial presentation to the ship's medical services and approximately $20 \mathrm{~h}$ after his first ever symptom. It is fortunate that he was still under active review and the ship was in port.

This case raises concerns over how best to manage the not infrequent scenario of a chest pain patient with no 
elevation of troponins in the maritime environment. These patients are at significant risk of death or infarction within the next 30 days if the diagnosis is unstable angina, but they will not get a full work-up to establish diagnosis prior to discharge from the ship's medical centre because no cruise ship has the capability for stress-testing or further imaging on board. It is also quite possible that these patients will not get stress-tested within $72 \mathrm{~h}$ of discharge either, as recommended [6]. The limitations of current investigational capabilities on board ships leave both the maritime physician and his patient in an unenviable position.

\section{CONCLUSIONS}

Over-reliance on shipboard troponin testing as a means of clearing a patient with ACS for discharge is a potentially hazardous strategy in that it fails to recognise patients with unstable angina. There is significant risk to morbidity and mortality in these patients if they are not diagnosed and treated. Ultimately, no matter how carefully one reviews, the correct diagnosis may still be missed in some of these cases.

\section{REFERENCES}

1. American College of Emergency Physicians. Health Care Guidelines for Cruise Ship Medical Facilities. July 2014 Revision. http://www. acep.org/Physician-Resources/Clinical/Health-Care-Guidelines -for-Cruise-Ship-Medical-Facilities (accessed 06 December 2014).

2. Hamm CW, Goldmann BU, Heeschen C et al. Emergency room triage of patients with acute chest pain by means of rapid testing for cardiac troponin T or troponin I. N Engl J Med 1997; 337: 1648-1653.

3. Das R, Kilcullen N, Morrell C et al. The British Cardiac Society Working Group definition of myocardial infarction: implications for practice. Heart 2006; 92: 21-26.

4. Morrow DA, Rifai N, Tanasijevic MJ et al. Clinical efficacy of three assays for cardiac troponin i for risk stratification in acute coronary syndromes: a thrombolysis in myocardial infarction (TIMI) 11B substudy. Clin Chem 2000; 46: 453-460.

5. Heidenreich PA, Alloggiamento T, Melsop $\mathrm{K}$ et al, The prognostic value of troponin in patients with non-ST elevation acute coronary syndromes: a meta-analysis. J Am Coll Cardiol 2001; 38: 478-485.

6. Amsterdam EA, Wenger NK, Brindis RG et al. 2014 ACC/AHA Guideline for the management of patients with non-ST elevation acute coronary syndromes: executive summary: a report of the American College of Cardiology/American Heart Association task force on practice guidelines. J Am Coll Cardiol 2014. doi:10.1016/j. jacc.2014.09.017. 